\title{
Theoretical considerations on the factors influencing the processing of hemp stalks
}

\author{
Paul Găgeanu, Mihai Olan, Iuliana Găgeanu*, and Alexandru Zaica \\ INMA Bucharest, 6, Ion Ionescu de la Brad Boulevard, Romania
}

\begin{abstract}
The present work is achieved based on the processing of the data accumulated over time, within the activity of research, technological engineering, and testing of machines for processing agricultural products in the last years, as well as studying the specialized literature with the latest achievements of some companies that make machinery for processing agricultural products. The compression of the hemp stalks for processing is analyzed, the main characteristics of the working rolls, the specific energy consumed are determined and an analysis of the obtained fiber length is performed. In order to develop a technical equipment for processing hemp stalks that ensures high performance, the following aspects were studied: the constructive and functional factors of a technical equipment that influence the working processes in order to choose a performance solution for processing hemp stalks. In the last part of the paper, the main technical and functional characteristics of a high-performance technical equipment for processing the hemp stalks harvested in green are established.
\end{abstract}

\section{Introduction}

Hemp is part of the group of textile plants of great value for human and industrial use.

Hemp (Figure 1) is one of the oldest cultivated plants (over 2000 years), being used mainly to obtain fibers used in clothing making. Hemp strains from indigenous (local) varieties and wild hemp contain $10-12 \%$ fiber, while improved varieties have $26-32 \%$ [1], [2].

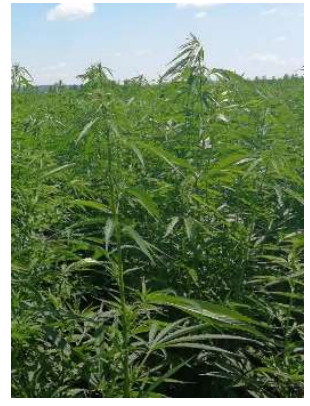

a

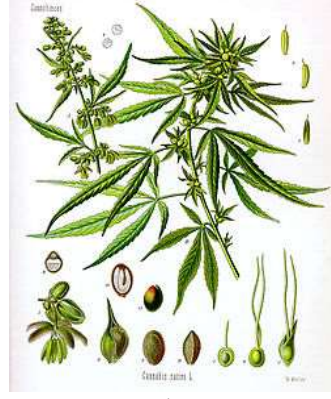

b

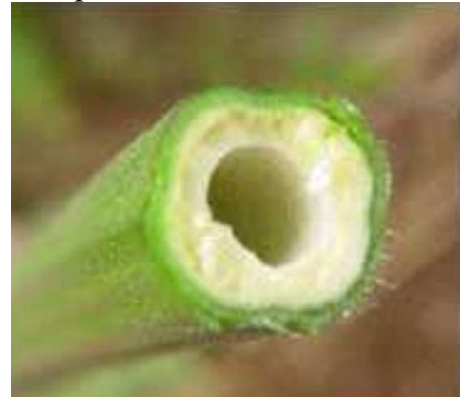

C

Fig. 1. Hemp plants

a) aerial parts; b) COmponents: root, stalks and fruits; c)green stalk section, [20], [21]

* Corresponding author: iuliadml@yahoo.com 
The fibers are very strong and that is why the stalk is difficult to cut, tangling on the blades of the combine - meaning that powerful cutting machines must be used, otherwise harvesting will be cumbersome [3]-[5].

The stalks should be cut as long as possible - long fibers are better and more useful than short ones. The areas cultivated with hemp in the world have been continuously reduced, reaching from over one million hectares in 1938, to about 425,000 ha in 1988 now under 400,000 ha are cultivated with hemp. The main cultivating countries are: Russia, India, Pakistan, Turkey, North Korea, Poland, Hungary, Bulgaria, Chile [6].

The hemp stalk from which the fibers are extracted is straight and has ramifications at the bottom. Its length is between 1 and $3 \mathrm{~m}$, and the thickness varies from 4 to $8 \mathrm{~mm}$. The anatomical tissues of the epidermis are more complex compared to that of flax [7].

Hemp stalks for textile fibers are assessed by: predominant color, which is usually yellow - green or yellow, length at a certain percentage of plants; thickness and moisture.

Mechanical breakage of the stems is known as decortication and results in the separation of free fibers from the less valuable wood core (waste) [8], [11].

The fiber content in the stalks is influenced by the variety, the technological and pedoclimatic conditions. Fibers have a number of properties that are particularly valuable in strength (traction, torsion, friction, rotting), extensibility (elastic and plastic), spinning capacity, length greater than the sisal, jute, manila or cotton fibers, making them usable in a great number of fields: in the textile industry, in the manufacturing industry, in the automotive industry, etc., [12], [13]

Basically, hemp processing for fiber must follow the procedures of harvesting, cutting, baling, pre-processing, peeling and cleaning. Leaving it longer in the field to dry further helps decortication. But recent research has shown that non-twisted "green decortication" is also acceptable for some industrial applications [14], [15]. In this case, green hemp decortication requires more power and energy than dry hemp and is less efficient [16].

\section{Material and method}

In order to obtain fibers from hemp stalks, they must go through a combined process of compressing the stems and crushing the woody part, detaching and separating them from the fibers. For this, two pairs of rollers are proposed to perform the above operations.

a) Compression: for the first phase (compression of stalks), the stalks from their initial thickness $d$ are pressed to thickness $s$ after passing through the first pair of rollers (Figure 2).

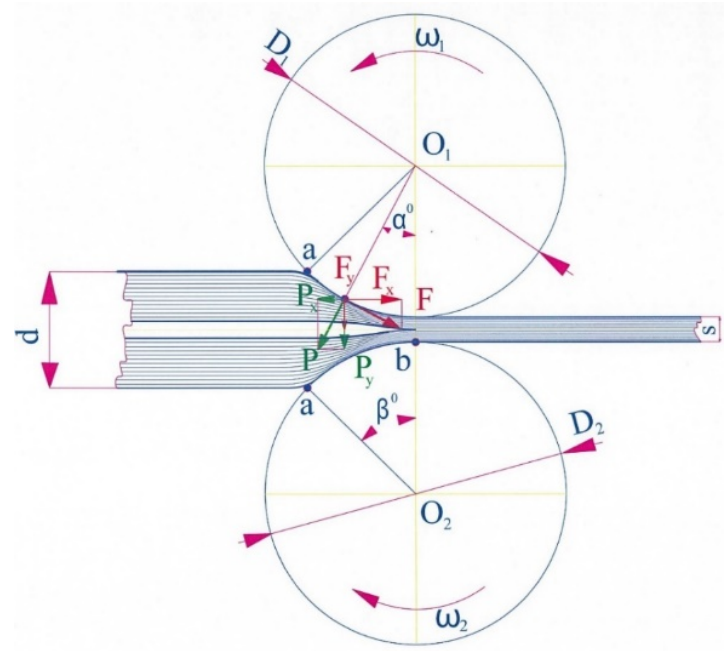


Fig. 2. Schematic diagram of compressing hemp stalks

The forces with which the rollers act on the stalk layer for each zone are directed perpendicular to the contact surface and can be reduced to a resultant force $P$. By decomposing this force in two directions perpendicular to the material compression and respectively its displacement, we obtain the components $P y$ which compresses the material and $P x$ which pushes the material from the passage. At the same time, the frictional forces acting on the surface of the rollers act tangentially, which can be presented by the resultant $F$. By decomposing the resultant force $F$, we obtain the components $F x$, which drive the material between the rollers and $F y$ which contributes to the pressing of the material.

Analyzing the process of compression (pressing) it is found that, when the rollers approach, simultaneous with decreasing the space $s$, the contact angle $\alpha^{o}$ increases. As it turns out, the condition of the material between the rollers is:

$$
F_{x} \geq P_{x}
$$

or

Friction force, is $F=P_{\operatorname{tg} \varphi}$

$$
F \cos _{\alpha} \geq P \sin _{\alpha}
$$

Replacing, we obtain

namely,

$$
P \operatorname{tg}_{\varphi} \cos _{\alpha} \geq P \sin _{\alpha}
$$

$$
\operatorname{tg}_{\varphi}>\operatorname{tg}_{\alpha}
$$

It is found that the thickness $s$ and the degree of compression $(\Delta s)$ of the stems, for pressing between two rollers, depend on the diameter of the rollers $D_{1}$ and $D_{2}$, and the coefficient of friction $(F=\operatorname{tg} \varphi)$ of the surface material of the roller. Therefore, the increase in diameter $D$ and the coefficient of friction, $\operatorname{tg}_{\varphi}$, ensures the compression of the larger diameter stems which improves the conditions of the stems' drive and increases the productivity of the compression (pressing) process $Q$ and the degree of crushing of the woody part of the stems.

\section{b) The working width of the roller}

It is estimated to work with hemp stalks where their overlap is involuntary. The working width of the rollers is given by relation:

where: $B$ - roller width, [m];

$$
B=\lambda * n * d+2 e
$$

$N$ - number of plants simultaneously processed, [-];

$d$ - diameter of plants simultaneously processed, [m];

$e$ - the distance at which the loading of the roller should be made in relation to the casing, $[\mathrm{m}] .(\mathrm{e}=20-30 \mathrm{~mm})$;

$\lambda$ - coefficient of flattening of the stalk after pressing $(\lambda=1,55 \doteqdot 1,59)$.

\section{c) The working capacity of the rollers}

The working capacity of a pair of rollers is given by the relation:

where: $s$ - distance between rollers, $[\mathrm{m}]$;

$$
\mathrm{G}=3600 * \mathrm{~B} * \mathrm{~s} * \mathrm{~V}_{\mathrm{p}} * \eta * \gamma
$$

$V_{p}$ - peripheral speed of rollers, $[\mathrm{m} / \mathrm{s}]$

$\eta$ - roller loading coefficient, $\eta=0,7-0,9$;

$\gamma$ - volumetric weight of hemp stalks, $\left[\mathrm{tf} / \mathrm{m}^{3}\right]$.

d) The peripheral speed of the rollers is given by the relation:

$$
V_{p}=\pi D_{n} / 60
$$

where: $D$ - rollers diameter, $[\mathrm{m}]$; 


\section{e) Specific energy consumed}

$n$ - rollers revolution frequency, [rot $/ \mathrm{min}]$.

The total specific energy could be simplified into two parts: the specific fiber processing energy and the specific core processing energy. Thus:

where: $E_{k}-$ total energy, $[\mathrm{J} / \mathrm{g}]$;

$$
E_{k}=\mu_{m} E_{m}+\mu_{f} E_{f}
$$

$E_{f}$ - fiber specific energy, $[\mathrm{J} / \mathrm{g}]$;

$E_{m}$ - core specific energy, $[\mathrm{J} / \mathrm{g}]$;

$\mu_{m}$ - the mass ratio of the basic fraction; [\%];

$\mu_{f}$. the mass ratio of the fiber fraction; [\%].

The core ratio $\mu_{m}$ and the fibers ratio $\mu_{f}$ are constant.

Researchers have presented different models to simulate the energy requirement for stalk processing. Theories regarding the specific energy of size reduction at the initial and final dimensions of the material have been developed. Among these theories, Kick, Rittinger and Bond laws on size reduction are the most widely known and widely accepted. Their theories are presented in the following equations [17] - [19]:

$$
\begin{gathered}
E_{k}=C_{k} * \ln \left(\frac{L_{l}}{L_{2}}\right) \\
E_{R}=C_{R} * \ln \left(\frac{1}{L_{2}}-\frac{1}{L_{1}}\right) \\
E_{B}=C_{B} * \ln \left(\frac{10}{\sqrt{L_{2}}}-\frac{10}{\sqrt{L_{1}}}\right)
\end{gathered}
$$

where: $E_{K}, E_{R}$ and $E_{B}$ - values for the specific energy of each law, [W];

$L_{1}$ and $L_{2}$ - initial dimension, respectively the final dimension of the material, [m];

$C_{K}, C_{R}$ and $C_{B}-$ constant factors, [-].

The following equation was used to evaluate the total decortication energy input for 5 seconds.

$$
E_{\text {total }}=y_{2}+y_{12} \times \Delta_{t}+y_{3}+y_{22} \times \Delta_{t}+\cdots+y_{n}+y_{n-12} \times \Delta_{t}(J)
$$

where: $y_{l}=$ the value of the power of the first data point, [W];

$y_{2}=$ the value of the power of the second data point, [W];

$y_{n}=$ the value of the power of the $\mathrm{n}^{\text {th }}$ data point, [W];

$\Delta t=$ time interval (periods), [s].

Specific energy is considered to be net energy divided by the supply mass.

where: $E_{S}$ - specific energy, [J / g];

$$
E_{s}=\frac{E_{\text {net }}}{M}
$$

$E_{\text {net }}-$ net energy, $[\mathrm{J}]$;

$M$ - feeding mass, [g].

\section{Results}

\section{Fiber length analysis}

The ratio between the final lengths of the core and the fibers is considered to be constant. The proportions of core and fiber content, being considered uniform, lead to the hypotheses:

1) the initial length of the core $L_{l m}$ is equal to the initial fiber length $L_{l f}$.

2) the relationship between the final length of the core and the fiber is:

$$
L_{2 m}=r \times L_{2 f}
$$


where: $L_{2 m}$ - final length of the core, [m];

$L_{2 f}$ - final length of the fiber, [m];

$r$ - constant, [-].

By taking the fibers and the fractional core separately, Kick's original law (9) can be expressed as follows:

$$
\begin{gathered}
E_{m}=C_{K m} * \ln \frac{L_{1 m}}{L_{2 m}} \\
E_{f}=C_{K f} * \ln \frac{L_{1 f}}{L_{2 f}}
\end{gathered}
$$

Replacing $\mathrm{L}_{1 \mathrm{c}}$ and $\mathrm{L}_{2 \mathrm{c}}$ with the terms $\mathrm{L}_{1 \mathrm{f}}$ and $\mathrm{L}_{2 \mathrm{f}}$, relation (8) becomes:

$$
\begin{gathered}
E_{k}=\mu_{m} * C_{k m} * \ln \frac{L_{1 f}}{r L_{2 f}}+\mu_{f}^{*} C_{k f} * \ln \frac{L_{1 c}}{L_{2 f}} \\
E_{k}=\left(\mu_{m} * C_{k m}+\mu_{f}^{*} C_{k f}\right) \ln \frac{L_{1 f}}{L_{2 f}}+\mu_{c} * C_{k m} * \ln \frac{1}{r}
\end{gathered}
$$

The final fiber length can vary over a wide range. From less than $20 \mathrm{~mm}$ to more than 1500 $\mathrm{mm}$. To take into account the distribution of the final fiber length, $\mathrm{E}_{\mathrm{k}}$ can be calculated as:

$$
E_{k}=\left(\mu_{m}{ }^{*} C_{k m}+\mu_{f}^{*} C_{k f}\right) * \ln \left(\sum_{i=1}^{n} \delta_{i} \frac{L_{1 f}}{L_{2 f i}}\right)+\mu_{m}{ }^{*} C_{k c} \ln \frac{1}{r}
$$

where: $\delta_{i}$ - mass proportion of the $i$ length category, [\%];

$n$ - number of length categories, [-];

$L_{2 f i}-$ average exit fiber length for $i$ length category, [m].

Equation (17) can be rewritten in the following general form:

$$
E_{K}=C_{K} * X_{K}+b_{K}
$$

where: $C_{K}$ - constant factor determined through experimental data, [-];

$b_{K}$ - constant term according to hypothesis, $[\mathrm{J} / \mathrm{k}]$;

$X_{K}-$ is $\ln \left(\sum_{i=1}^{n} \delta_{i} \frac{L_{1 f}}{L_{2 f i}}\right)$ and was an independent variable in Kick's modified law.

Equation (19) is Kick's modified law for determining the specific energy for hemp decortication. This modified law is related to the total energy correlated with the initial and final length of the fiber fraction.

Similarly, the modified laws of Rittinger and Bond are as follows:

$$
\begin{gathered}
E_{R}=\left(\frac{\mu_{m}{ }^{*} C_{R m}}{r}+\mu_{f} C_{R f}\right) * \sum_{i=1}^{n} \delta_{i}\left(\frac{1}{L_{2 f i}}-\frac{1}{L_{l f}}\right)+\left(\frac{\mu_{m}{ }^{*} C_{R c}}{L_{l f}}\right) \\
\mathrm{E}_{\mathrm{R}}=\mathrm{C}_{\mathrm{R}} * \mathrm{X}_{\mathrm{R}}+\mathrm{b}_{\mathrm{R}} \\
E_{B}=\left(\frac{\mu_{m} C_{B m}}{\sqrt{r}}+\mu_{f} * C_{B f}\right) * \sum_{i=1}^{n} \delta_{i}\left(\frac{10}{\sqrt{L_{2 f i}}}-\frac{10}{\sqrt{L_{l f}}}\right)+\left(\frac{10 * \mu_{m} * C_{B m}}{\sqrt{L_{l f i}} * \sqrt{r}}-\frac{10 * \mu_{m} C_{B m}}{\sqrt{L_{l f}}}\right. \\
\mathrm{E}_{\mathrm{B}}=\mathrm{C}_{\mathrm{B}} * \mathrm{X}_{\mathrm{B}}+\mathrm{b}_{\mathrm{B}}
\end{gathered}
$$

$B_{R}$ and $b_{B}(J / g)$ variable are coefficients dependent on the initial length of fibers. In calculus, the initial length of fibers is considered unchanged.

Based on these theoretical results, the optimal technology and working diagram of a hemp stalks processing equipment were established (Figure 3). The proposed technical equipment consists of the following components: a feeding table, (1), with a hat under which the plants pass, (3), a pair of drums with discs serving as feed guides, (4), a pair of toothed rollers for the primary pressing and crushing of the stems (6), a pair of pallet rollers that provide the splitting of the wood part (7), a pair of crushing rollers, (8), a roller with displacement pallets (9), a third pair of grooved rollers to ensure a deeper crushing of the woody part of the stem, (10), another dislocation roller (11), a last pair of rollers with 
grooved surface which ensures the advanced crushing of the woody part (12) and a rotary dislodge with the latticework (13).

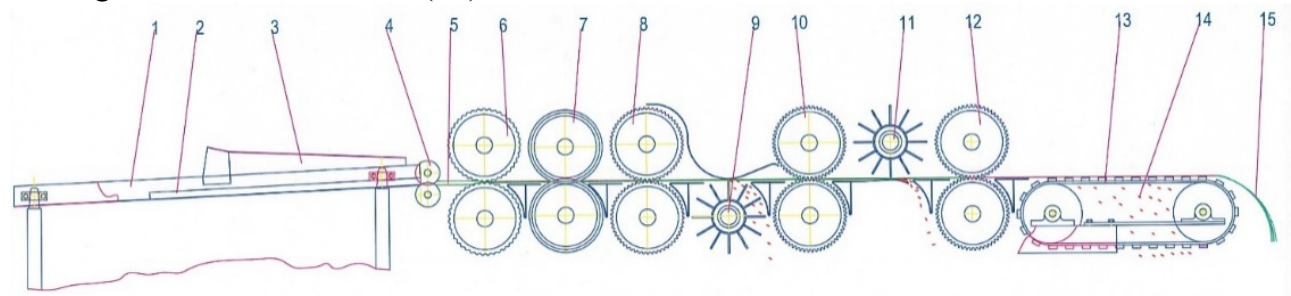

Fig. 3. Hemp stalks processing equipment

1. feeding table; 2. guides; 3. hood; 4. rollers with guide rolls; 5 . hemp stalk; 6 . flat rollers; 7. splitting rollers; 8 . crush rollers $i$; 9 . displacement roller $i$; 10 . crushing rollers ii; 11 . displacement roller ii; 12. crushing rollers iii; 13. dislodge iii; 14. hurd; 15. fiber

$\begin{array}{lll}\begin{array}{c}\text { Main technical and functional characteristics } \\ \text { - capacity processed stalks }\end{array} & \mathrm{kg} / \mathrm{h} & \\ \text { - feeding } & - & \begin{array}{l}1000-2000 ; \\ \text { manual }\end{array} \\ \text { - overall dimensions: } & \mathrm{mm} & \\ \quad \text { - length } & \mathrm{mm} & 5100 ; \\ \text { - width } & \mathrm{mm} & 1600 ; \\ \text { - height } & \mathrm{mm} & 2400 ; \\ \text { - feeding table size L x l } & & -9 \\ \text { - number of operation stages } & \mathrm{kW} & 22 \\ \text { - installed power } & \mathrm{mm} & 6-20 \\ \text {-stalks diameter } & & \end{array}$

In the front of the frame and adjacent to the inside end of the feeding table is mounted a pair of rollers as feed guides which consist of a pair of stationary shafts spaced apart from one another at an adjustable distance from one another depending on the thickness of plant stems.

On these stationary shafts are provided a plurality of discs mounted at a distance given by rubber sheaths mounted on the two shafts serving as separators through which the plants pass.

These shafts are positioned so that the discs on one shaft are fastened so that they are in the middle of the distance between two discs on the other shaft ensuring contact with the fed stems and pushing them to the first pair of rollers that do the processing.

The distance between the two shafts is adjustable depending on the diameter of the stalks of the material to be fed. The plant, under the pressure of the disc with which it is in contact, is drawn and, at the same time, the leaves on the stem are detached in contact with the other two discs and by free fall they are evacuated.

From here, the plant passes between the flattening rollers where it is flattened, after which it is inserted between the splitting rollers where it is longitudinally split, and the obtained strips are passed among the first crushing rollers where the woody part of the stem begins to be crushed. Part of the crushed wood is dislodged by the first pallet roller and is evacuated.

What is left is passed between the two pairs of crushing rollers. After passing through them, a large part of the wood is crushed and after the passage of the second pallet roller it is dislodged from the fibers and is evacuated.

Next, the fiber with the wood part that did not break off is passed between the rollers of the third pair of crushing rollers. The crushed wood portion is detached from the fiber mass when passing over the third dislodging roller which has different construction from the other two. It is fixed on an independent shaft on which there are two bearings with two flanges on which are mounted blades (lattices). These blades are mounted evenly on the rubber or leather straps. 
In order to ensure an even better dislodging, at the extension roller head is provided with a vibrating system that during operation accelerates the process of dislodging the hurd.

The finished fiber product from the last pair of rollers is transported and removed from the machine. At the same time, a share of the wood parts is eliminated by detaching them from the fiber mass when they come in contact with the latticework.

The decortication process is completed in around 5 seconds. For each power-time curve, the 5 -second width of the peak-containing curve is chosen to calculate the energy. The results are presented in Figure 4.

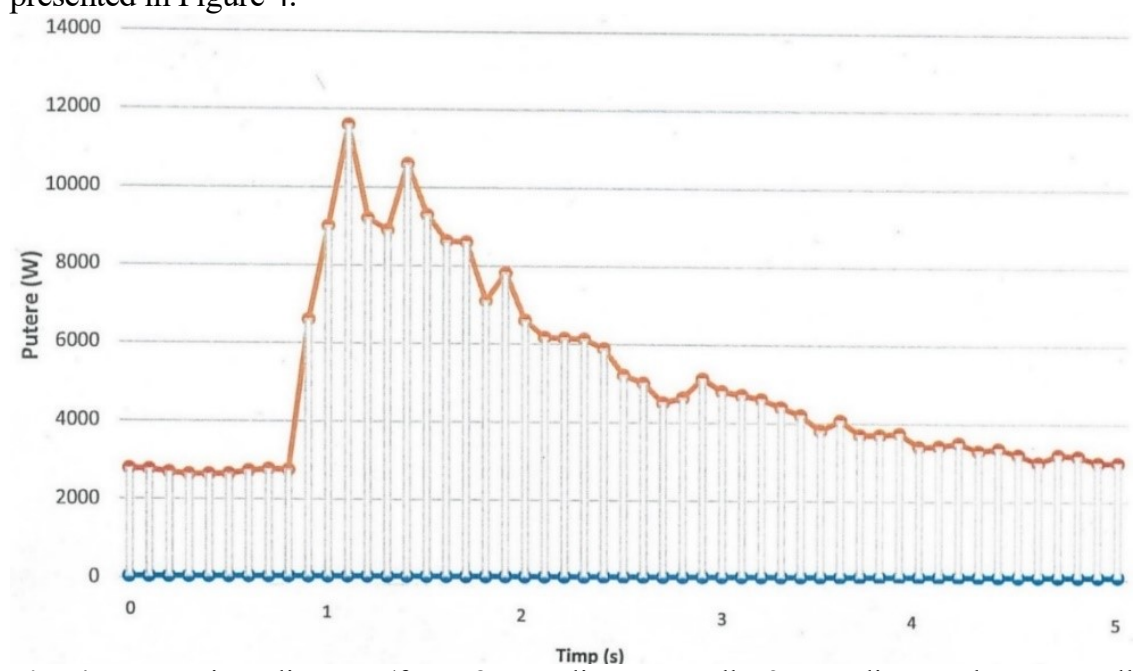

Fig. 4. Power-time diagram (for a $8 \mathrm{~mm}$ diameter stalk, $3 \mathrm{~mm}$ distance between rollers and 240 $\mathrm{g} /$ stalk feeding mass)

The horizontal line before the bell shape curve shown in Figure 4 represents the power consumption in idle phase. In order to determine the net energy consumption, the energy in the phase idle is deducted from the total energy obtained from the above equation.

The energy consumption in load is about 4.8 times greater compared to the idle consumption. Fiber length differs from hybrid to hybrid and depends on the length and thickness of the stalk and the peripheral speeds of the rollers.

\section{Conclusions}

Hemp crops are constantly growing in size, due to their multiple benefits for various industries. Therefore, the development of a technical equipment that capitalizes these crops and is accessible for farmers is very important.

By developing this equipment, we obtain a top machine for processing hemp stalks, a modern machine allowing the separation of a large amount of fibers from the mass of the stalks.

The equipment can be used with remarkable results when processing hemp stalks from small or medium-sized farms. The equipment can be transported on specific means of transport to the places where the processing of hemp stalks is required.

\section{Acknowledgement}

This work was supported by a grant of the Romanian Education and Research Ministry, on NUCLEU Program, Project "Foundation of the technology for harvesting and primary processing of hemp stalks in green", code PN 191001 03, ctr. 5N/2019, and a grant on Programme 1 - Development of the national research-development system, subprogramme 1.2 - Institutional performance - Projects for financing excellence in RDI, contract no. 16PFE. 


\section{References}

1. Devi B. - All about the hemp plant: 10,000 years of history, Hemp, Inc. - Stock Trading Symbol OTC HEMP, 2015;

2. Idler C., Pecenka R., Fürll C., Gusovius H.J. - Wet Processing of Hemp: An Overview, Journal of Natural Fibers, Volume 8, 2011 - Issue 2, pp. 59-80;

3. Jinke X. - Analysis and Design of Hemp Fibre Decorticators, A Thesis submitted to the Faculty of Graduate Studies of The University of Manitoba in partial fulfilment of the requirements of the degree of Master of Science, 2010;

4. Clarke R.C. - Traditional Fiber Hemp (Cannabis) Production, "Processing, Yarn Making, and Weaving Strategies-Functional Constraints and Regional Responses. Part 1", Journal of Natural Fibers, Volume 7- Issue 2, 2010, pp. 118-153;

5. Clarke R.C. - Traditional Fiber Hemp (Cannabis) Production, "Processing, Yarn Making, and Weaving Strategies-Functional Constraints and Regional Responses. Part 2", Journal of Natural Fibers, Volume 7- Issue 3, 2010, pp. 229-250;

6. Small agriculture encyclopaedia, Encyclopaedical Publishing House, Bucharest, 1988 ;

7. Sankari H. - Towards best fibre production in Finland: stem and fibre yields and mechanical fibre properties of selected fibre hemp and linseed genotypes; Academic Dissertation, Faculty of Agriculture and Forestry of the University of Helsinki, 24 March, 2000;

8. International Publication Number WO 2006/094359 A1 Title: Apparatus and method for processing of plant material;

9. Leduc P.J., Hill L.G., Kelly D.H., Stratton M.A. - Method for decorticating plant material, United States Patent, Patent Number: 5,720,083/Feb. 24, 1998;

10. Chen L.H., Verdes R.P. - Decorticating machine with variable speed feed and beater rollers, United States Patent nr.5465464/16. Nov.1995;

11. Patterson D.E - Machine for decorticating fiber-bearing stalks and leaves, United States Patent nr. 2480602/30 august 1948;

12. Scheleceen G. W. - Means for treating fiber-bearing plans, United States Patent nr. $1,308,376 / 1$, July 1919 ;

13. Formation Ag, Decortication equipment, Updated January $8^{\text {th }}, 2019$;

14. Munder F., Furll C., Effective Processing of Bast Fiber Plants and Mechanical Properties of the Fibers, An ASAE/CSAE Meeting Presentation, Canada, 2004;

15. Riddlestone S., Stott E., Blackburn K., Brighton J. - A Technical and Economic Feasibility Study of Green Decortication of Hemp Fibre for Textile Uses, Journal of Industrial Hemp 11(2), 2006, pp. 25-55;

16. Baker M.I., Chen Y., Lague C., Landry C., Peng. Q., Zhong W., Wang J. - Hemp fibre decortications using a planetaryball mill, Canadian Biosystems Engineering. Volume 52, 2010, pp. 7-15;

17. Kick, F.M., The law of proportional resistors and its application felix. Leipzig, Germany. 1885;

18. Bond, F.C. The third theory of comminution. Trans. AIME, vol. 193, 1952. pp. 484 494;

19. von Rittinger P.R. - Lehrbuch der aufbereitungskunde in ihrer neunten entwicklung und ausbildung systematisch dargestellt, Ernst und Korn Publishing House, 1867;

20. https://www.futura-sciences.com/maison/dossiers/isolation-isolation-naturellesolution-plein-essor-906/page/10/;

21. https://ro.wikipedia.org/wiki/C\%C3\%A2nep $\% \mathrm{C} 4 \% 83$ indian $\% \mathrm{C} 4 \% 83$. 